\title{
Fitomassa e cobertura do solo de culturas de sucessão ao milho na Região do Cerrado
}

\author{
Joilson Sodré Filho ${ }^{(1)}$, Alexandre Nunes Cardoso(2), Ricardo Carmona(1) e Arminda Moreira de Carvalho(2)
}

(1) Universidade de Brasília, Fac. de Agronomia e Medicina Veterinária, Caixa Postal 4508, CEP 70910-970 Brasília, DF. E-mail: alexc@cpac.embrapa.br, arminda@cpac.embrapa.br

Resumo - O objetivo deste trabalho foi avaliar a produção de biomassa e cobertura do solo de diferentes espécies em sucessão ao milho cultivado nos sistemas convencional e plantio direto em condições de Cerrado. Avaliou-se a produção de biomassa de aveia-preta, crotalária júncea, feijão-bravo-do-ceará, guandu, mucuna, girassol e milheto, quando apresentavam $50 \%$ de florescimento. A cobertura do solo foi determinada aos $30 \mathrm{e}$ 60 dias após a semeadura das culturas de sucessão, em agosto (período da seca), em outubro (depois das primeiras chuvas) e na cultura do milho, aos 15 e aos 45 dias após a sua semeadura. A mucuna foi a espécie que apresentou a maior taxa de cobertura do solo durante seu crescimento. A produção de biomassa do girassol não foi eficiente na cobertura do solo. $\mathrm{O}$ sistema plantio direto apresenta maior produção de biomassa pelas culturas de cobertura em relação ao sistema convencional.

Termos para indexação: adubos verdes, plantas de cobertura, sistema plantio direto, manejo do solo.

\section{Phytomass and soil cover of sequential crops after maize in Cerrado region}

Abstract - The objective of this study was to evaluate the biomass production and soil cover by different crops after maize cultivated in conventional tillage and no-tillage, in Cerrado conditions. The biomass of black oat, sunnhep, canavalia, pigeonpea, mucuna, sunflower and millet was obtained when they showed $50 \%$ of flowering. Soil coverage was evalluated at 30 and 60 days after sequential crops sowing, in August (during dry season), in October (at the beginning of the rainy season) and after 15 and 45 days of maize crop sowing. Mucuna showed the highest soil coverage rate during its growing. The biomass produced by sunflower had no efficiency for soil coverage. No-tillage showed the highest productions of biomass by sequential crops, compared to the conventional tillage system.

Index terms: green manures, cover crops, no-tillage, soil management.

\section{Introdução}

O uso e a ocupação agrícola do Cerrado têm tido, nos últimos anos, grande avanço, porém sem considerar aspectos corretos de manejo e conservação do solo. A busca de novas tecnologias é fundamental na agricultura moderna, estabelecida em bases conservacionistas.

A rotação de culturas durante o período de entressafra, geralmente, no inverno, é recomendável em sistemas que objetivem uma agricultura sustentável, visando à diversificação das atividades na propriedade (Ambrosano et al., 1997; Chaves \& Calegari, 2001). A utilização de culturas destinadas à cobertura do solo é estratégica na melhoria da qualidade ambiental, atenuando-se problemas do monocultivo.
A escolha de espécies vegetais para introdução nos sistemas de culturas depende da adaptação delas às condições de clima de cada região e do interesse do produtor (Silva \& Rosolem, 2001). Segundo Alvarenga et al. (2001) e Chaves \& Calegari (2001) as espécies escolhidas devem crescer bem em condições de baixa a média fertilidade do solo, e devem ter capacidade de adaptação a baixos valores de $\mathrm{pH}$ do solo (Ernani et al., 2001). A produção de fitomassa das espécies utilizadas como cobertura é decorrente das condições climáticas, edáficas e fitossanitárias (Amado et al., 2002) e principalmente do seu sistema radicular. Quanto mais o sistema radicular penetrar no solo, tanto maior será a produção de biomassa, além de promover a descompactação do solo. 
As espécies utilizadas como cobertura do solo na Região do Cerrado devem apresentar rusticidade, crescimento inicial rápido e alta produção de biomassa na época da seca (Carvalho \& Sodré Filho, 2000). Amabile et al. (2000) citam que uma das principais limitações ao uso de plantas de cobertura nessa Região é a época de semeadura. Segundo Argenta et al. (2001), o uso de espécies leguminosas é pouco utilizado como cobertura durante o inverno, por limitações como crescimento inicial lento, maior custo de aquisição de sementes em relação a outras espécies e a alta taxa de decomposição de seus resíduos.

A escolha da espécie que será semeada em sucessão é também determinante no sucesso do sistema plantio direto (Argenta et al., 2001; Oliveira et al., 2002). Segundo Ceretta et al. (2002), o sucesso do plantio direto depende da manutenção de sistemas capazes de gera quantidades de matéria seca suficientes para manter o solo coberto durante todo o ano, o que significa que áreas destinadas às culturas de primavera-verão não devem permanecer em pousio durante o inverno. O sistema plantio direto propicia a antecipação da semeadura por dispensar o tempo gasto no preparo do solo. Conforme Alvarenga et al. (2001), $6 \mathrm{t} \mathrm{ha}^{-1}$ de matéria seca na superfície é a quantidade suficiente para se obter boa cobertura do solo.

O objetivo deste trabalho foi avaliar a produção de biomassa e cobertura do solo por diferentes culturas de sucessão ao milho cultivado nos sistemas convencional e plantio direto, em condições de Cerrado.

\section{Material e Métodos}

O trabalho foi realizado na Embrapa Cerrados, Planaltina, DF, no ano de 2001, em uma área cultivada há quatro anos com milho seguido de diferentes culturas de sucessão, num Latossolo Vermelho-Amarelo, textura argilosa, cuja análise química e granulométrica (0-20 cm de profundidade) revelou inicialmente os seguintes resultados: $\mathrm{pH}$ em água, 6,$2 ; \mathrm{MO}, 23,6 \mathrm{~g} \mathrm{dm}^{-3}$. $\mathrm{Al}^{3+}, 0,01 \mathrm{cmol}_{\mathrm{c}} \mathrm{dm}^{-3} ; \mathrm{Ca}^{2+}+\mathrm{Mg}^{2+}, 3,3 \mathrm{cmol}_{\mathrm{c}} \mathrm{dm}^{-3}$; $\mathrm{H}^{+}+\mathrm{Al}^{3+}, 3,34 \mathrm{cmol}_{\mathrm{c}} \mathrm{dm}^{-3} ; \mathrm{P}, 3,4 \mathrm{mg} \mathrm{dm}^{-3} ; \mathrm{K}^{+}, 0,11 \mathrm{cmol}_{\mathrm{c}} \mathrm{dm}^{-3}$; areia grossa, $48 \mathrm{~g} \mathrm{~kg}^{-1}$; areia fina, $253 \mathrm{~g} \mathrm{~kg}^{-1}$; silte, $186 \mathrm{~g} \mathrm{~kg}^{-1}$; argila, $513 \mathrm{~g} \mathrm{~kg}^{-1}$. Aplicaram-se a lanço $180 \mathrm{~kg} \mathrm{ha}^{-1}$ de $\mathrm{P}_{2} \mathrm{O}_{5}, 60 \mathrm{~kg} \mathrm{ha}^{-1}$ de $\mathrm{K}_{2} \mathrm{O}, 50 \mathrm{~kg} \mathrm{ha}^{-1}$ de FTE BR-10 e $500 \mathrm{~kg} \mathrm{ha}^{-1}$ de gesso, antes da cultura do milho, no seu primeiro ano de cultivo.

O clima do local foi classificado como do tipo Aw (Köppen), com duas estações bem definidas (seca e chuvosa). Os dados referentes às médias de temperatura e precipitação pluvial acumulada durante o ano de 2001 na área experimental encontram-se na Figura 1.

O milho foi cultivado no sistema convencional de preparo do solo (SPC), com a incorporação dos resíduos das culturas de sucessão, com uma aração e duas gradagens e no sistema plantio direto (SPD). As espécies usadas como culturas de sucessão foram as seguintes: aveia-preta (Avena strigosa Schieb.), crotalária júncea (Crotalaria juncea L.), feijão-bravodo-ceará (Canavalia brasiliensis M. e Benth), guandu cv. Caqui (Cajanus cajan (L.) Millsp), mucuna (Mucuna cochinchinensis (Lour) A. Chevalier), girassol (Helianthus annuus L.) e milheto BN-2 (Pennisetum glaucum (L.) R. Brown). A testemunha consistiu na ausência de culturas de sucessão ao milho, com o crescimento natural da vegetação espontânea.

O delineamento experimental adotado foi de blocos ao acaso com parcelas subdivididas em três repetições. As espécies que sucederam ao milho representavam as parcelas, e os sistemas de preparo do solo, as subparcelas. O tamanho das parcelas era de $12 \times 30 \mathrm{~m} \mathrm{e}$ das subparcelas, de $12 \times 15 \mathrm{~m}$, com $1 \mathrm{~m}$ nas laterais como bordadura, totalizando uma área útil de $130 \mathrm{~m}^{2}$ por subparcela.

A semeadura das culturas de sucessão ocorreu em 5 de abril de 2001. A densidade e o espaçamento utilizados encontram-se na Tabela 1 . Todas as espécies foram semeadas diretamente sobre os restos culturais do milho, utilizando-se semeadeira para plantio direto, nos dois sistemas de manejo do solo. Em relação à mucuna e ao feijão-bravo-do-ceará, utilizou-se semeadeira manual em virtude do tamanho de suas sementes, que fo-

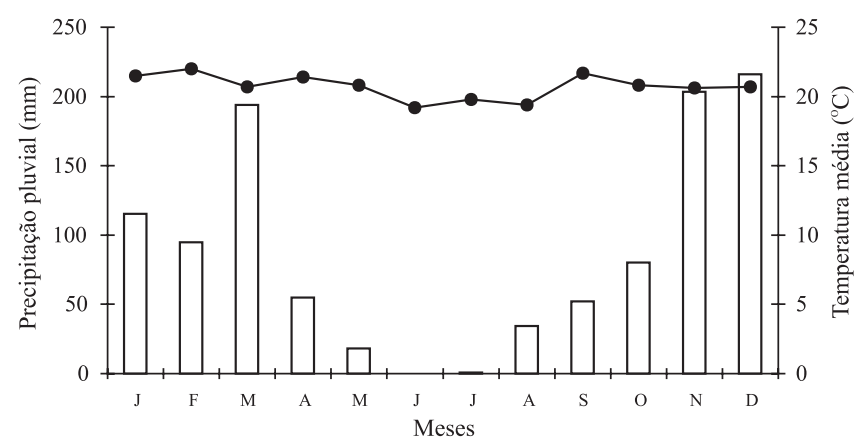

Figura 1. Precipitação pluvial ( $\square$ ) e temperatura média $(\bullet)$ mensais no ano de 2001 na área experimental da Embrapa Cerrados, Planaltina, DF. 
ram imersas em água quente por 30 e 45 segundos, respectivamente, para superar a dormência e uniformizar a emergência (Carvalho \& Sodré Filho, 2000).

Quando cada espécie de sucessão apresentou 50\% de floração, as plantas foram roçadas, permanecendo como cobertura morta até a semeadura do milho. No momento do corte, foram retiradas duas amostras de $1 \mathrm{~m}^{2}$ de cada subparcela para determinação da massa de matéria verde e seca. As amostras foram secadas em estufa a $65^{\circ} \mathrm{C}$, até atingirem peso constante e, em seguida, pesadas.

$\mathrm{Na}$ avaliação da cobertura do solo, utilizou-se uma moldura de madeira de $50 \mathrm{~cm}$ de lado, com uma rede de barbantes espaçados a cada $5 \mathrm{~cm}$ onde se observou a presença de cobertura proporcionada pelas culturas de sucessão e pelas plantas daninhas nas interseções da rede de barbantes (Alvarenga, 1993). As amostragen foram feitas aos 30 e 60 dias após a semeadura das culturas de sucessão (DAS). A determinação da cobertura morta, da presença de plantas daninhas e da rebrotação das culturas de sucessão foi realizada em agosto de 2001 (meados do período da seca) e em outubro (depois das primeiras chuvas), quando todas as culturas de sucessão já estavam roçadas. Também se determinou a cobertura do solo por resíduos e pelas plantas daninhas, durante o ciclo da cultura do milho, em suas entrelinhas, aos 15 e 45 dias após a semeadura do milho (DASM). Em todas as avaliações foram feitas quatro amostragens por subparcela, com o lançamento ao acaso da moldura de madeira, totalizando $1 \mathrm{~m}^{2}$.

Antes da semeadura do milho, foi aplicada na área experimental uma mistura de $1,5 \mathrm{~L} \mathrm{ha}^{-1}$ de glyphosate + 1,5 $\mathrm{L} \mathrm{ha}^{-1}$ de 2,4-D, no sistema plantio direto, para dessecação das plantas daninhas adultas e das culturas de sucessão que apresentavam rebrotação.

Tabela 1. Densidade de semeadura e ciclo das culturas de sucessão ao milho por ocasião de $50 \%$ de seu florescimento.

\begin{tabular}{lccr}
\hline Espécie & $\begin{array}{c}\text { Espaço entre } \\
\text { linhas }(\mathrm{m})\end{array}$ & $\begin{array}{c}\text { Sementes } \\
\mathrm{m}^{-1}\end{array}$ & Ciclo (dias) \\
\hline Aveia-preta & 0,40 & 40 & 116 \\
Crotalária júncea & 0,20 & 20 & 67 \\
Feijão-bravo-do-ceará & 0,40 & 10 & 113 \\
Girassol & 0,80 & 4 & 88 \\
Guandu & 0,40 & 20 & 97 \\
Milheto & 0,20 & 45 & 95 \\
Mucuna & 0,40 & 10 & 109 \\
\hline
\end{tabular}

O milho híbrido de ciclo superprecoce (Cargill 901) foi semeado no início da estação chuvosa, em 31 de outubro de 2001, no espaçamento de $0,90 \mathrm{~m}$ e estande final de 65.000 plantas ha-1. Aplicaram-se $30 \mathrm{~kg} \mathrm{ha}^{-1} \mathrm{de}$ $\mathrm{N}, 150 \mathrm{~kg} \mathrm{ha}^{-1}$ de $\mathrm{P}_{2} \mathrm{O}_{5}$ e $80 \mathrm{~kg} \mathrm{ha}^{-1}$ de $\mathrm{K}_{2} \mathrm{O}$ no sulco de semeadura, além de $50 \mathrm{~kg}^{-1}$ de $\mathrm{Ne} 60 \mathrm{~kg} \mathrm{ha}^{-1} \mathrm{de}_{2} \mathrm{O}$ em cobertura, por ocasião da emissão da sexta folha. A dose de $\mathrm{N}$ foi repetida quando a planta apresentou o oitavo par de folhas.

Os dados foram submetidos à análise de variância e as médias comparadas pelo teste de Duncan, a 5\% de probabilidade.

\section{Resultados e Discussão}

O período vegetativo das culturas de sucessão até $50 \%$ de seu florescimento variou de 116 dias na aveiapreta a 67 dias na crotalária júncea (Tabela 1). No tratamento sem cultura de sucessão, esse período foi em média de 77 dias.

As culturas de sucessão apresentaram baixa produção de fitomassa, provavelmente, em virtude do período de semeadura não ser favorável ao seu desenvolvimento (Tabela 2). As médias de massa de matéria seca foram inferiores a 6,0 $\mathrm{t} \mathrm{ha}^{-1}$ que, segundo Alvarenga et al. (2001), é a quantidade adequada de resíduos que proporciona boa taxa de cobertura do solo. As baixas produtividades de matéria seca foram conseqüência da baixa produção de matéria fresca (Oliveira et al., 2002).

Amado et al. (2002) classificam as plantas de cobertura conforme sua produção de fitomassa. De acordo com os autores e com os resultados de massa de matéria seca, as culturas de sucessão podem ser classificadas como de baixa produção: aveia-preta, guandu e milheto; média produção: crotalária júncea, girassol e mucuna; e como de alta produção: feijão-bravo-do-ceará (Tabela 2).

O girassol, por adaptar-se às condições de baixa pluviosidade do período de safrinha na Região do Cerrado, apresentou maior massa de matéria verde, seguido da mucuna e do feijão-bravo-do-ceará (Tabela 2). Esse comportamento do girassol já era esperado pelo alto teor de lignina e celulose em seus tecidos (Carvalho \& Sodré Filho, 2000), os quais proporcionam maior quantidade de matéria fresca e seca. Porém, esse fator não resultou em melhor cobertura do solo, em virtude da estrutura de seus resíduos, constituídos predominantemente por hastes ou caules. 
A mucuna e o feijão-bravo-do-ceará também apresentaram grande produção de biomassa e demonstraram rusticidade durante o período de deficiência hídrica, por causa do sistema radicular agressivo, que absorve água e nutrientes a maiores profundidades do solo (Alvarenga et al., 1995), aliado ao longo período vegetativo da mucuna (109 dias) e do feijão-bravo-doceará (113 dias) (Tabela 1).

Os menores valores médios de massa de matéria seca foram apresentados pela aveia-preta, pelo guandu, pelo milheto e pelo tratamento sem cultura de sucessão (Tabela 2). Segundo Amabile et al. (2000), no guandu ocorrem acentuadas reduções na biomassa quando se atrasa sua semeadura; por ser sensível ao fotoperíodo, quando é semeado em janeiro e março, os dias curtos acarretam diminuição da fase vegetativa.

A aveia-preta, embora tenha grande histórico de uso como planta de cobertura e de sucessão à cultura principal, na Região Sul do Brasil (Argenta et al., 2001) não apresentou boa adaptação às condições de entressafra do Cerrado, quanto à produção de biomassa e cobertura do solo, com massa de matéria seca de $1.243 \mathrm{~kg} \mathrm{ha}^{-1}$ (Tabela 2). Derspch \& Calegari (1992) citam valores de 2 a $6 \mathrm{t} \mathrm{ha}^{-1}$ quando essa espécie é semeada em ambiente de clima subtropical, favorável ao seu crescimento. Barradas et al. (2001) constataram produção de $7,44 \mathrm{t} \mathrm{ha}^{-1}$ de matéria seca, quando a aveia-preta foi cultivada na região serrana fluminense, em solo não adubado.

O sistema plantio direto foi superior ao sistema convencional de preparo do solo em relação à produção de fitomassa (Tabela 2). Segundo Theisen \& Vidal (1999) e Alvarenga et al. (2001), o plantio direto propicia ambiente favorável ao estabelecimento das culturas de sucessão e, conseqüentemente, maior produção de biomassa. Além disso, nesse sistema o acúmulo de resíduos sucessivos de safras e entressafras não permite que o solo permaneça descoberto. A elevada produção de biomassa nesse sistema será vantajosa durante a seca e nas primeiras semanas de estabelecimento da cultura comercial, protegendo o solo contra variações de temperatura e também do impacto das gotas de chuvas fortes, comuns nesses períodos.

Na avaliação realizada aos 30 dias após a semeadura das culturas de sucessão (DAS), a mucuna foi a espécie que proporcionou maior cobertura do solo, diferenciando-se significativamente das demais (Tabela 3). Isso pode ter ocorrido por causa do hábito de crescimento prostrado da mucuna, o que permitiu que suas folhas e ramos se espalhassem pelo solo, proporcionando maior cobertura (Favero et al., 2001). Também pode ter contribuído para esse resultado o rápido crescimento dessa espécie que, aos 30 DAS, já se apresentava adaptada às condições de baixa precipitação na época da sua semeadura e desenvolvimento, coincidindo com o início da estação de seca no Cerrado.

Nessa época de avaliação, os menores índices de cobertura foram observados no guandu e no girassol, possivelmente porque ambos apresentam crescimento ereto. Este fato pode ter prejudicado as avaliações, já que a cobertura proporcionada pelas plantas era observada por cima da armação de madeira, de maneira vertical. Além disso, o guandu possui crescimento inicial mais lento (Favero et al., 2001), como verificado

Tabela 2. Matéria verde e seca $\left(\mathrm{kg} \mathrm{ha}^{-1}\right)$ das culturas de sucessão no sistema de preparo convencional do solo (SPC) e no sistema plantio direto (SPD), por ocasião de $50 \%$ de seu florescimento ${ }^{(1)}$.

\begin{tabular}{|c|c|c|c|c|c|c|}
\hline \multirow[t]{2}{*}{ Espécie } & \multicolumn{3}{|c|}{ Matéria verde } & \multicolumn{3}{|c|}{ Matéria seca } \\
\hline & SPC & SPD & Média & SPC & SPD & Média \\
\hline Aveia-preta & $3.645 \mathrm{cA}$ & $2.693 \mathrm{cA}$ & $3.169 \mathrm{f}$ & $1.298 \mathrm{aA}$ & $1.188 \mathrm{bA}$ & $1.243 \mathrm{de}$ \\
\hline Crotalária júncea & $6.218 \mathrm{bA}$ & $7.273 \mathrm{bA}$ & $6.745 \mathrm{~cd}$ & $2.147 \mathrm{aA}$ & $2.412 \mathrm{abA}$ & $2.280 \mathrm{~b}$ \\
\hline Feijão-bravo-do-ceará & $6.300 \mathrm{bB}$ & $9.716 \mathrm{bA}$ & $8.008 \mathrm{bc}$ & $2.605 \mathrm{aA}$ & $3.470 \mathrm{aA}$ & $3.038 \mathrm{a}$ \\
\hline Girassol & $8.233 \mathrm{aB}$ & $12.316 \mathrm{aA}$ & $10.275 \mathrm{a}$ & $1.957 \mathrm{aB}$ & $2.855 \mathrm{bA}$ & $2.406 \mathrm{~b}$ \\
\hline Guandu & $4.333 \mathrm{bcA}$ & $5.033 \mathrm{bcA}$ & $4.683 \mathrm{ef}$ & $1.661 \mathrm{aA}$ & $1.963 \mathrm{bA}$ & $1.812 \mathrm{c}$ \\
\hline Milheto & $5.000 \mathrm{bB}$ & $7.183 \mathrm{bA}$ & $6.091 \mathrm{de}$ & $1.335 \mathrm{aA}$ & $1.892 \mathrm{bA}$ & $1.613 \mathrm{~cd}$ \\
\hline Mucuna & $8.933 \mathrm{aA}$ & $8.633 \mathrm{bA}$ & $8.783 \mathrm{ab}$ & $2.627 \mathrm{aA}$ & 2.438abA & $2.532 \mathrm{~b}$ \\
\hline Sem cultura de sucessão & $4.856 \mathrm{bA}$ & $3.276 \mathrm{cA}$ & $4.066 \mathrm{f}$ & $1.382 \mathrm{aA}$ & $663 \mathrm{cB}$ & $1.132 \mathrm{e}$ \\
\hline Sistemas & $5.940 \mathrm{~B}$ & $7.015 \mathrm{~A}$ & & $1.876 \mathrm{~B}$ & $2.110 \mathrm{~A}$ & \\
\hline
\end{tabular}

(1)Médias seguidas das mesmas letras, minúsculas nas colunas e maiúsculas nas linhas, não diferem entre si a 5\% de probabilidade pelo teste de Duncan; os coeficientes de variação em relação às médias de matéria verde e seca foram de 11,12\% e 15,58\%, respectivamente. 
aos 30 DAS. No caso dessas espécies, a alternativa seria diminuir a distância entre as linhas, de forma a adensar as plantas e permitir maior porcentagem de cobertura do solo. Derspch \& Calegari (1992) recomendam o espaçamento reduzido do girassol quando o objetivo for a cobertura rápida do solo e a produção de fitomassa.

O milheto é muito cultivado como safrinha no Cerrado como cobertura do solo no sistema plantio direto (Alvarenga et al., 2001), por apresentar, entre outras vantagens, facilidade de semeadura, adaptação à deficiência hídrica e grande persistência de seus resíduos sobre o solo. No entanto, seu crescimento nos primeiros 30 dias foi lento, permanecendo dessa forma até o corte. Esperava-se que essa espécie apresentasse boa capacidade de estabelecimento inicial, principalmente, por possuir alta resistência à seca (Chaves \& Calegari, 2001) e estar adaptada às condições não favoráveis ao seu desenvolvimento, como a baixa pluviosidade do período.

As culturas de sucessão que apresentaram maior cobertura do solo foram as que proporcionaram menores índices de cobertura pelas plantas daninhas aos $30 \mathrm{e}$ aos 60 DAS (Tabela 3). No caso da mucuna, isso pode ser atribuído ao seu crescimento rápido e prostrado, à competição por água, luz, nutrientes e espaço, e à elevada produção de matéria verde, corroborando os resultados de Calegari (1995) e Chaves \& Calegari (2001).

Tabela 3. Cobertura do solo pelas culturas de sucessão e pelas plantas daninhas, aos 30 e 60 dias após a sua semeadura (DAS), no sistema de preparo convencional do solo (SPC) e no sistema plantio direto (SPD) $)^{(1)}$.

\begin{tabular}{lccccc}
\hline Espécie & \multicolumn{2}{c}{30 DAS } & & \multicolumn{2}{c}{60 DAS } \\
\cline { 2 - 3 } \cline { 5 - 6 } & $\begin{array}{c}\text { Culturas de } \\
\text { sucessão (\%) }\end{array}$ & $\begin{array}{c}\text { Plantas } \\
\text { daninhas (\%) }\end{array}$ & & $\begin{array}{c}\text { Culturas de } \\
\text { sucessão (\%) }\end{array}$ & $\begin{array}{c}\text { Plantas } \\
\text { daninhas (\%) }\end{array}$ \\
\hline Aveia-preta & $30 \mathrm{~b}$ & $4 \mathrm{c}$ & & $34 \mathrm{~b}$ & $10 \mathrm{~b}$ \\
Crotalária júncea & $28 \mathrm{bc}$ & $4 \mathrm{c}$ & & $32 \mathrm{bc}$ & $11 \mathrm{~b}$ \\
Feijão-bravo- & & & & & \\
do-ceará & $27 \mathrm{bc}$ & $6 \mathrm{bc}$ & & $33 \mathrm{bc}$ & $10 \mathrm{~b}$ \\
Girassol & $16 \mathrm{~d}$ & $5 \mathrm{~b}$ & & $9 \mathrm{e}$ & $6 \mathrm{~b}$ \\
Guandu & $14 \mathrm{~d}$ & $8 \mathrm{~b}$ & & $20 \mathrm{de}$ & $9 \mathrm{~b}$ \\
Milheto & $22 \mathrm{~cd}$ & $8 \mathrm{~b}$ & & $28 \mathrm{bcd}$ & $8 \mathrm{~b}$ \\
Mucuna & $39 \mathrm{a}$ & $3 \mathrm{c}$ & & $60 \mathrm{a}$ & $9 \mathrm{~b}$ \\
Sem cultura & & & & & \\
de sucessão & $26 \mathrm{bc}$ & $26 \mathrm{a}$ & & $22 \mathrm{~cd}$ & $22 \mathrm{a}$ \\
\hline SPC & $25 \mathrm{a}$ & $15 \mathrm{a}$ & & $29 \mathrm{a}$ & $13 \mathrm{a}$ \\
SPD & $25 \mathrm{a}$ & $14 \mathrm{a}$ & & $31 \mathrm{a}$ & $14 \mathrm{a}$ \\
\hline CV (\%) & 20,14 & 59,52 & & 35,15 & 26,01 \\
\hline (1) Médias seguidas da mesma letra, nas colunas, não diferem entre si a
\end{tabular}

$5 \%$ de probabilidade pelo teste de Duncan
Aos 60 DAS, quando a maioria das culturas de sucessão já estava florescendo, resultados semelhantes à avaliação anterior (30 DAS) foram observados, destacando a mucuna como cobertura verde (Tabela 3). Essa espécie apresentou os maiores índices de crescimento, cobrindo $60 \%$ do solo. Favero et al. (2001) encontraram diferenças entre as épocas avaliadas de crescimento de adubos verdes, aos 28 e 56 dias após a sua emergência, observando que, na segunda época, a pressão de competição se pronunciou, principalmente, para a mucuna-preta, que foi uma das espécies que recobriram maior porcentagem do solo $(99,75 \%)$

O tratamento sem cultura de sucessão foi o que apresentou maior porcentagem de cobertura de plantas daninhas, como já era esperado, por causa da diversidade de espécies de invasoras e da ausência de uma cultura que estabeleça condições de sombreamento do solo, dificultando o desenvolvimento das plantas daninhas (Tabela 3).

Na avaliação da cobertura do solo realizada em agosto (período da seca), na maioria das culturas de sucessão, constatou-se elevada porcentagem de cobertura pelos resíduos, acima de $70 \%$, sempre superiores à testemunha (Tabela 4). A incidência de plantas daninhas no período da seca foi baixa, indicando a influência da rebrotação das culturas de sucessão.

Depois das primeiras chuvas, houve redução da cobertura do solo em todas as espécies por causa das condições climáticas do local, como altas temperaturas e precipitação elevada, favorecendo a decomposição dos resíduos. Além disso, as leguminosas apresentam material vegetal de baixa relação $\mathrm{C} / \mathrm{N}$ (Tabela 5). No caso do feijão-bravo-do-ceará, a redução de cobertura foi de $73 \%$ para seis por cento. No entanto, nessa espécie, a rebrotação atenuou a alta taxa de decomposição apresentada, o que contribuiu para a menor porcentagem de plantas daninhas (Tabela 4). Na rebrotação do feijãobravo-do-ceará, não houve problemas na semeadura direta do milho, pois o controle foi viabilizado com a aplicação de herbicida.

O milheto apresentou elevadas taxas de cobertura, nas duas épocas de avaliação, isto é, em agosto e em outubro, depois das primeiras chuvas. Por se tratar de uma gramínea utilizada na formação de palhada, o maior tempo de permanência de seus resíduos deve-se à sua alta relação $\mathrm{C} / \mathrm{N}$ (Tabela 5), proporcionando maior resistência à decomposição e uniformidade de distribuição sobre o solo (Alvarenga et al., 2001; Oliveira et al., 2002). 
Tabela 4. Cobertura do solo por resíduos de culturas de sucessão, pelas plantas daninhas e pela rebrotação das culturas de sucessão, em agosto (período da seca) e outubro (depois das primeiras chuvas), no sistema de preparo convencional do solo (SPC) e no sistema plantio direto (SPD) $)^{(1)}$.

\begin{tabular}{|c|c|c|c|c|c|c|}
\hline \multirow[t]{2}{*}{ Espécie } & \multicolumn{3}{|c|}{ Agosto } & \multicolumn{3}{|c|}{ Outubro } \\
\hline & $\begin{array}{l}\text { Resíduos } \\
(\%)\end{array}$ & $\begin{array}{c}\text { Plantas } \\
\text { daninhas }(\%)\end{array}$ & $\begin{array}{c}\text { Rebrotação } \\
(\%)\end{array}$ & $\begin{array}{l}\text { Resíduos } \\
\text { (\%) }\end{array}$ & $\begin{array}{c}\text { Plantas } \\
\text { daninhas (\%) }\end{array}$ & $\begin{array}{c}\text { Rebrotação } \\
(\%)\end{array}$ \\
\hline Aveia-preta & $81 \mathrm{a}$ & $5 b$ & $7 \mathrm{c}$ & $32 \mathrm{ab}$ & $50 \mathrm{ab}$ & $10 \mathrm{bc}$ \\
\hline Crotalária júncea & $87 \mathrm{a}$ & $4 \mathrm{~b}$ & 3de & $50 \mathrm{a}$ & $27 \mathrm{bc}$ & $13 b c$ \\
\hline Feijão-bravo-do-ceará & 73ab & $5 b$ & $15 \mathrm{~b}$ & $6 \mathrm{~b}$ & $11 \mathrm{c}$ & $75 a$ \\
\hline Girassol & $71 \mathrm{ab}$ & $3 b$ & $0 \mathrm{e}$ & $40 \mathrm{a}$ & $31 b$ & $3 c$ \\
\hline Guandu & $80 \mathrm{a}$ & $6 \mathrm{~b}$ & 4 cde & $29 \mathrm{ab}$ & $31 b$ & $24 b$ \\
\hline Milheto & $83 a$ & $7 \mathrm{~b}$ & $2 \mathrm{e}$ & $31 \mathrm{ab}$ & $49 \mathrm{ab}$ & $8 \mathrm{bc}$ \\
\hline Mucuna & $82 \mathrm{a}$ & $4 \mathrm{~b}$ & $8 \mathrm{c}$ & $29 \mathrm{ab}$ & $38 \mathrm{~b}$ & $23 \mathrm{~b}$ \\
\hline Sem cultura de sucessão & $54 \mathrm{~b}$ & $20 \mathrm{a}$ & $20 \mathrm{a}$ & $29 \mathrm{ab}$ & $64 \mathrm{a}$ & $64 \mathrm{a}$ \\
\hline SPC & $74 a$ & $7 \mathrm{a}$ & $7 \mathrm{a}$ & $30 \mathrm{a}$ & $37 \mathrm{a}$ & $24 \mathrm{~b}$ \\
\hline SPD & $81 \mathrm{a}$ & $6 \mathrm{a}$ & $7 \mathrm{a}$ & $31 \mathrm{a}$ & $40 \mathrm{a}$ & $31 \mathrm{a}$ \\
\hline$\overline{\mathrm{CV}(\%)}$ & 16,19 & 60,69 & 31,71 & 42,22 & 36,95 & 40,46 \\
\hline
\end{tabular}

${ }^{(1)}$ Médias seguidas da mesma letra, nas colunas, não diferem entre si a 5\% de probabilidade pelo teste de Duncan.

Tabela 5. Relação C/N das espécies utilizadas em sucessão ao milho.

\begin{tabular}{lcc}
\hline Espécie & Caule & Folha + flor \\
\hline Crotalária & 26,90 & 11,73 \\
Feijão-bravo-do-ceará & 36,65 & 13,75 \\
Girassol & 80,82 & 13,04 \\
Guandu & 35,28 & 13,02 \\
Milheto & 91,50 & 22,18 \\
Mucuna & 38,35 & 13,51 \\
Vegetação espontânea & 23,95 & 21,71
\end{tabular}

Fonte: modificado de Carvalho \& Sodré Filho (2000).

As elevadas taxas de rebrotação, apresentadas pela mucuna e pelo feijão-bravo-do-ceará, confirmam a utilização dessas plantas para fins de sucessão e cobertura no período de entressafra na Região do Cerrado. O sistema radicular de ambas espécies merece destaque por sua capacidade de absorção de água e nutrientes a maiores profundidades, ampliando a exploração do solo. Alvarenga et al. (1995) constataram que o sistema radicular do feijão-bravo-do-ceará atinge $159 \mathrm{~cm}$ de profundidade e boa nodulação e que as raízes da mucuna-preta penetram mais de $1 \mathrm{~m}$ de profundidade.

Durante o desenvolvimento da cultura do milho, aos 15 e 45 dias após a sua semeadura (DASM), no sistema plantio direto, as médias de cobertura do solo foram elevadas, diferindo, significativamente, do sistema convencional, pelo fato de não se revolver o solo, o que facilita o acúmulo de resíduos anteriores à semeadura da cultura comercial (Tabela 6). A presença de resíduos no sistema plantio direto protege o solo das chuvas de alta erosividade, comuns no início do período chuvoso no Cerrado.

Houve redução do índice de cobertura do solo entre as duas avaliações durante o desenvolvimento inicial da cultura do milho, e essa redução foi evidenciada em relação às leguminosas. Como aos 45 DASM, as folhas do milho já começam a cobrir o solo, protegendo-o de agentes erosivos, a elevada decomposição dos resíduos pode ser compensada no que se refere à proteção do solo.

Foi observada maior porcentagem de cobertura pelas plantas daninhas no sistema plantio direto, em ambas as épocas de amostragem (Tabela 6). Nesse sistema, existe maior concentração de sementes de plantas daninhas aptas para germinar na superfície. Por estarem concentradas na superfície, muitas vezes até sobre a massa de resíduos em decomposição, as sementes interferem na dinâmica da comunidade infestante (Theisen \& Vidal, 1999), prevalecendo aquelas com maior capacidade de produção de biomassa. No entanto, as plântulas não completam desenvolvimento por não conseguirem ultrapassar a barreira de resíduos vegetais existente no solo (Paes \& Rezende, 2001), permitindo, no sistema plantio direto, controle eficiente das plantas daninhas.

Os resultados revelam que o uso de culturas de sucessão ao milho no Cerrado pode ser promissor, quando se leva em conta sua produção de biomassa e adaptação às condições de entressafra na Região. A seleção 
Tabela 6. Cobertura do solo pelos resíduos das culturas de sucessão e pelas plantas daninhas aos 15 e 45 dias após a semeadura da cultura do milho (DASM) no sistema de preparo convencional do solo (SPC) e no sistema plantio direto (SPD) ${ }^{(1)}$.

\begin{tabular}{|c|c|c|c|c|c|c|c|c|c|}
\hline \multirow{4}{*}{$\begin{array}{l}\text { Espécie } \\
\text { Aveia-preta }\end{array}$} & \multicolumn{4}{|c|}{15 DASM } & \multicolumn{5}{|c|}{45 DASM } \\
\hline & \multicolumn{2}{|c|}{ Resíduos } & \multicolumn{2}{|c|}{ Plantas daninhas } & \multicolumn{2}{|c|}{ Resíduos } & \multicolumn{3}{|c|}{ Plantas daninhas } \\
\hline & \multirow{2}{*}{$\begin{array}{c}\mathrm{SPC}(\%) \\
0 \mathrm{aB}\end{array}$} & \multirow{2}{*}{$\begin{array}{c}\text { SPD (\%) } \\
89 \mathrm{aA}\end{array}$} & \multirow{2}{*}{$\begin{array}{l}\mathrm{SPC}(\%) \\
0 \mathrm{aB}\end{array}$} & \multirow{2}{*}{$\begin{array}{c}\mathrm{SPD}(\%) \\
2 \mathrm{bA}\end{array}$} & \multirow{2}{*}{$\begin{array}{c}\mathrm{SPC}(\%) \\
0 \mathrm{aB}\end{array}$} & \multirow{2}{*}{$\frac{\text { SPD (\%) }}{50 \mathrm{bA}}$} & \multirow{2}{*}{$\begin{array}{c}\mathrm{SPC}(\%) \\
26 \mathrm{aA}\end{array}$} & \multicolumn{2}{|c|}{ SPD $(\%)$ Média (\%) } \\
\hline & & & & & & & & $40 \mathrm{aA}$ & $33 a$ \\
\hline Crotalária júncea & $0 \mathrm{aB}$ & 84abA & $0 \mathrm{aB}$ & $5 \mathrm{bA}$ & $0 \mathrm{aB}$ & $51 \mathrm{bA}$ & $25 \mathrm{aA}$ & $44 \mathrm{aA}$ & $35 \mathrm{a}$ \\
\hline Feijão-bravo-do-ceará & $0 \mathrm{aB}$ & $86 \mathrm{abA}$ & $0 \mathrm{aB}$ & $6 \mathrm{bA}$ & $0 \mathrm{aB}$ & $65 \mathrm{aA}$ & $25 \mathrm{aA}$ & $30 \mathrm{aA}$ & $27 \mathrm{a}$ \\
\hline Girassol & $0 \mathrm{aB}$ & $81 \mathrm{abA}$ & $0 \mathrm{aB}$ & $8 \mathrm{bA}$ & $0 \mathrm{aB}$ & $56 \mathrm{bA}$ & $8 \mathrm{bB}$ & $34 \mathrm{aA}$ & $21 \mathrm{a}$ \\
\hline Guandu & $0 \mathrm{aB}$ & $85 \mathrm{abA}$ & $0 \mathrm{aB}$ & $1 \mathrm{bA}$ & $0 \mathrm{aB}$ & $56 \mathrm{bA}$ & $27 \mathrm{aA}$ & $36 \mathrm{aA}$ & $32 \mathrm{a}$ \\
\hline Milheto & $0 \mathrm{aB}$ & $90 \mathrm{aA}$ & $0 \mathrm{aB}$ & $2 \mathrm{bA}$ & $0 \mathrm{aB}$ & $53 \mathrm{bA}$ & $26 \mathrm{aA}$ & $40 \mathrm{aA}$ & $26 a$ \\
\hline Mucuna & $0 \mathrm{aB}$ & $87 \mathrm{aA}$ & $0 \mathrm{aB}$ & $6 \mathrm{bA}$ & $0 \mathrm{aB}$ & $59 \mathrm{bA}$ & $23 \mathrm{aA}$ & $29 \mathrm{aA}$ & $33 \mathrm{a}$ \\
\hline$\underline{\text { Sem cultura de sucessão }}$ & $0 \mathrm{aB}$ & $74 \mathrm{bA}$ & $0 \mathrm{aB}$ & $18 \mathrm{aA}$ & $0 \mathrm{aB}$ & $44 \mathrm{bA}$ & $13 \mathrm{bB}$ & $49 \mathrm{aA}$ & $31 \mathrm{a}$ \\
\hline Sistemas & OB & $84 \mathrm{~A}$ & OB & $6 \mathrm{~A}$ & OB & $53 \mathrm{~A}$ & $22 \mathrm{~B}$ & $38 \mathrm{~A}$ & 40,4 \\
\hline
\end{tabular}

(1)Médias seguidas das mesmas letras, minúsculas nas colunas e maiúsculas nas linhas, não diferem entre si a 5\% de probabilidade pelo teste de Duncan.

de espécies rústicas, que tolerem a falta de chuvas nesse período, aliada à persistência de seus resíduos e à liberação de nutrientes, devem ser levados em consideração quando se visa o correto manejo e conservação do solo. A persistência dos resíduos durante as épocas críticas do ano no Cerrado, como a estação seca, depois das primeiras chuvas e durante o início do desenvolvimento da cultura comercial, atenuará a radiação solar direta e a ação de agentes erosivos, como o impacto das gotas de chuva, comuns nesses períodos.

\section{Conclusões}

1. A mucuna é a espécie que apresenta maior cobertura do solo.

2. A produção de biomassa pelo girassol não é eficiente como cobertura do solo.

3. O sistema plantio direto proporciona maior acúmulo de biomassa pelas culturas de sucessão.

\section{Referências}

ALVARENGA, R.C. Potencialidades de adubos verdes para conservação e recuperação de solos. 1993. 112p. Tese (Doutorado) - Universidade Federal de Viçosa, Viçosa

ALVARENGA, R.C.; CABEZAS, W.A.L.; CRUZ, J.C.; SANTANA D.P. Plantas de cobertura de solo para sistema plantio direto. Inform Agropecuário, v.22, p.25-36, 2001.

ALVARENGA, R.C.; COSTA, L.M. da; MOURA FILHO, W. REGAZZI, A.J. Características de alguns adubos verdes de interesse para a conservação e recuperação de solos. Pesquisa Agropecuária Brasileira, v.30, p.175-185, 1995.
AMABILE, R.F.; FANCELLI, A.L.; CARVALHO, A.M. de. Comportamento de espécies de adubos verdes em diferentes épocas de semeadura e espaçamentos na região dos Cerrados. Pesquisa Agropecuária Brasileira, v.35, p.47-54, 2000.

AMADO, T.J.C.; MIELNICZUK, J.; AITA, C. Recomendações de adubação nitrogenada para o milho no RS e SC adaptada ao uso de culturas de cobertura do solo, sob sistema plantio direto. Revista Brasileira de Ciência do Solo, v.26, p.241-248, 2002.

AMBROSANO, E.J.; WUTKE, E.B.; TANAKA, R.T.; MASCARENHAS, H.A.A.; BRAGA, N.R.; MURAOKA, T. Leguminosas para adubação verde: uso apropriado em rotação de culturas. Campinas: Coordenadoria de Assistência Técnica Integral, 1997. 24p. Apostila

ARGENTA, G.; SILVA, P.R.F. da; FLECK, N.G.; BORTOLINI, C.G.; NEVES, R.; AGOSTINETTO, D. Efeitos do manejo mecânico e químico da aveia-preta no milho em sucessão e no controle do capim-papuã. Pesquisa Agropecuária Brasileira, v.36, p.851-860, 2001

BARRADAS, C.A.A.; FREIRE, L.R.; ALMEIDA, D.L. de DE-POLLI, H. Comportamento de adubos verdes de inverno na região serrana fluminense. Pesquisa Agropecuária Brasileira, v.36, p.1461-1468, 2001.

CALEGARI, A. Leguminosas para adubação verde de verão no Paraná. Londrina: Iapar, 1995. 118p. (Circular, 80).

CARVALHO, A.M. de; SODRÉ FILHO, J. Uso de adubos verdes como cobertura do solo. Planaltina: Embrapa-CPAC, 2000. 20p. (Boletim de Pesquisa, 11)

CERETTA, C.A.; BASSO, C.J.; FLECHA, A.M.T.; PAVINATO, P.S.; VIEIRA, F.C.B.; MAI, M.E.M. Manejo da adubação nitrogenada na sucessão aveia preta/milho, no sistema plantio direto. Revista Brasileira de Ciência do Solo, v.26, p.163-171, 2002.

CHAVES, J.C.D.; CALEGARI, A. Adubação verde e rotação de culturas. Informe Agropecuário, v.22, p.53-60, 2001. 
DERSPCH, R.; CALEGARI, A. Plantas para adubação verde de inverno. 2.ed. Londrina: Iapar, 1992. 80p. (Circular, 73).

ERNANI, P.R.; BAYER, C.; FONTOURA, S.M.V. Influência da calagem no rendimento de matéria seca de plantas de cobertura e adubação verde, em casa de vegetação. Revista Brasileira de Ciência do Solo, v.25, p.897-904, 2001

FAVERO, C.; JUCKSCH, I.; ALVARENGA, R.C.; COSTA, L.M.

da. Modificações na população de plantas espontâneas na presença

de adubos verdes. Pesquisa Agropecuária Brasileira, v.36, p.13551362, 2001

OLIVEIRA, T.K. de; CARVALHO, G.J. de; MORAES, R.N. de S.
Plantas de cobertura e seus efeitos sobre o feijoeiro em plantio direto. Pesquisa Agropecuária Brasileira, v.37, p.1079-1087, 2002.

PAES, J.M.V.; REZENDE, A.M. de. Manejo de plantas daninhas no sistema plantio direto na palha. Informe Agropecuário, v.22, p.3742, 2001

SILVA, R.H.; ROSOLEM, C.A. Crescimento radicular de espécies utilizadas como cobertura decorrente da compactação do solo. Revista Brasileira de Ciência do Solo, v.25, p.253-260, 2001.

THEISEN, G.; VIDAL, R.A. Efeito da cobertura do solo com resíduos de aveia preta nas etapas do ciclo de vida do capim-marmelada. Planta Daninha, v.17, p.189-196, 1999.

$\overline{\text { Recebido em } 13 \text { de junho de } 2003 \text { e aprovado em } 27 \text { de janeiro de } 2004}$ 